\title{
The "end" and "start" effects in iterated Prisoner's Dilemma
}

\author{
ANATOL RAPOPORT and PHILLIP S. DALE ${ }^{1}$ \\ Mental Health Research Institute, The University of Michigan
}

In the experiments on Prisoner's Dilemma reported by Rapoport and Chammah (1965), the games were typically iterated 300 times by each pair of players (sometimes 350 times or 700 times). Each run was interrupted every 25 plays, and the pause was used to add up the points won or lost by each of the players. The outcomes of the plays were recorded by the subjects themselves on data sheets divided into 25 -entry columns. Thus each subject was always aware when the first and last play of each 25-play block occurred.

Let us take a 50-play block as a unit and compute the mean frequency of $\mathrm{C}$ responses for the first, the 25th, the 26th, and the 50 th play, averaged over all such blocks in each experimental condition. The results are shown in Table 1 . We observe the following:

(1) In all of the 14 independent sets of data, without exception, the mean frequency of $\mathrm{C}$ responses on the 25th play is smaller than that on the first play. (The significance of this result by the two-sided sign test is $\mathrm{p}<.0002$.)

(2) With one possible exception, the mean frequency of $\mathrm{C}$ choices is greater on

${ }^{1}$ The research work on which this paper is based was supported by the National Institutes of Health Grant MH-4238-06, Mental Health Research Institute, The University of Michigan. the 26th play than on the 25th play ( $p<$ $.0004)$.

(3) With one exception, the mean frequency of $\mathrm{C}$ is smaller on the 50th play than on the 26 th play $(p<.005)$.

(4) The mean frequency on the first play is approximately equal to that on the 26th; the mean frequency on the 25th play is approximately equal to that on the 50th.

In short, we observe an "end" effect, specifically a decline in the probability of $\mathrm{C}$ on the last play of each 25-play block, and a "start" effect, specifically a greater frequency of $\mathrm{C}$ on the first play of each 25-play block. It should be noted that the first-play mean includes also the 51st, the 101st, etc., plays of each experimental session; likewise, the 25 th play includes also the 75 th, the 125th, etc. Therefore the difference between the first-play mean and the 25th-play mean cannot be attributed to the initial decline in the frequency of $\mathrm{C}$ choices, which is typically observed in iterated Prisoner's Dilemma, since this difference would be masked in the mean of the subsequent increase of $\mathrm{C}$ choices during the latter phases of the runs, which is also typically observed. We are dealing here with the end and start effects within each 25play block.

The source of the end effect readily suggests itself. Consider a finite run of iter- 
TABLE 1

\begin{tabular}{lcccccc}
\hline $\begin{array}{c}\text { Experi- } \\
\text { ment }{ }^{\mathrm{a}}\end{array}$ & $\mathrm{C}_{\mathbf{1}}$ & $\mathrm{C}_{25}$ & $\mathrm{C}_{28}$ & $\mathrm{C}_{50}$ & $\begin{array}{c}\text { No. of } \\
\text { pairs }\end{array}$ & $\begin{array}{c}\text { No. of } \\
\text { 25-play } \\
\text { blocks }\end{array}$ \\
\hline 201 & .62 & .49 & .62 & .53 & 70 & 840 \\
$201 \mathrm{~W}$ & .45 & .26 & .43 & .25 & 70 & 840 \\
$201 \mathrm{C}$ & .54 & .42 & .54 & .40 & 70 & 840 \\
202 & .56 & .41 & .55 & .42 & 29 & 348 \\
203 & .40 & .29 & .38 & .27 & 70 & 840 \\
204 & .66 & .57 & .60 & .57 & 10 & 120 \\
205 & .54 & .51 & .51 & .50 & 10 & 280 \\
206 & .44 & .41 & .44 & .46 & 10 & 280 \\
207 & .66 & .53 & .62 & .53 & 70 & 980 \\
208 & .66 & .42 & .71 & .43 & 9 & 108 \\
$209 \mathrm{~W}$ & .43 & .36 & .43 & .36 & 31 & 372 \\
$210 \mathrm{~W}$ & .32 & .36 & .36 & .30 & 100 & 200 \\
211 & .76 & .68 & .75 & .65 & 50 & 600 \\
$211 \mathrm{~W}$ & .66 & .56 & .64 & .61 & 50 & 600 \\
\hline
\end{tabular}

The populations and games used in each experiment are given at the end of the text.

ated Prisoner's Dilemma, in which the number of plays to be played is known to both players. We can expect that, whatever tacit cooperation may have been established in the course of the run, there will be defections on the last play, because there is everything to gain and nothing to lose from such a defection: no retaliation can follow. In our case, the 25th play is not the very last play of the session. However, the fact that the run is interrupted after every 25 th play may contribute to an end effect, since the 25th play is a last play of each "subrun" (i.e., no immediate retaliation can follow). This conjecture is strongly corroborated by the fact that the 26th play is almost exactly the same as the first. Thus a start effect seems to be also operating, as if the average player were encouraged to "try cooperating" at the start of each 25run block.

Figure 1 is a plot of the mean $\mathrm{C}$ frequencies for every play of the 50-run block averaged over all such blocks (649 pairs of players, 7,248 blocks). Here we observe the entire average 50-play time course. There is a short initial decline following
TABLE 2

\begin{tabular}{cc}
\hline Plays & Decline of C \\
\hline $24-25$ & .00 \\
$49-50$ & .02 \\
$74-75$ & .04 \\
$99-100$ & .04 \\
$124-125$ & .01 \\
$144-150$ & .03 \\
$174-175$ & .03 \\
$199-200$ & .03 \\
$224-225$ & .04 \\
$249-250$ & .02 \\
$274-275$ & .02 \\
$299-300$ & .06 \\
\hline
\end{tabular}

the start effect. Then the mean frequency of $\mathrm{C}$ remains practically constant until about four plays from the end, at which time the end effect sets in, presumably as the players anticipate the final defection.

We might also inquire whether the final end effect, i.e., the decline of average $\mathrm{C}$ from the 299th play to the 300th, is larger than the periodic end effects. To see this, we have tabulated the successive end effects for each of the 25-play blocks. The results are shown in Table 2. The final end effect is indeed larger than any of the others. Moreover, there is no discernible trend. The increase in the final end effect occurs suddenly.

The end effect is observed also in the short runs of Prisoner's Dilemma reported by Lynn Morehous in this issue (Morehous, 1966). Note that the mean frequency of $C$ choices on the second play of a two-play run is smaller than that of the first play. This, however, could also be attributed to the "initial decline" effect, since predominantly less cooperation is observed on the second play than on the first in any iterated Prisoner's Dilemma (cf. Rapoport and Chammah, 1965, p. 89).

Observe, however, that the mean frequency of $\mathrm{C}$ on the fifth play of a five-play run is smaller than that on the fourth. The 


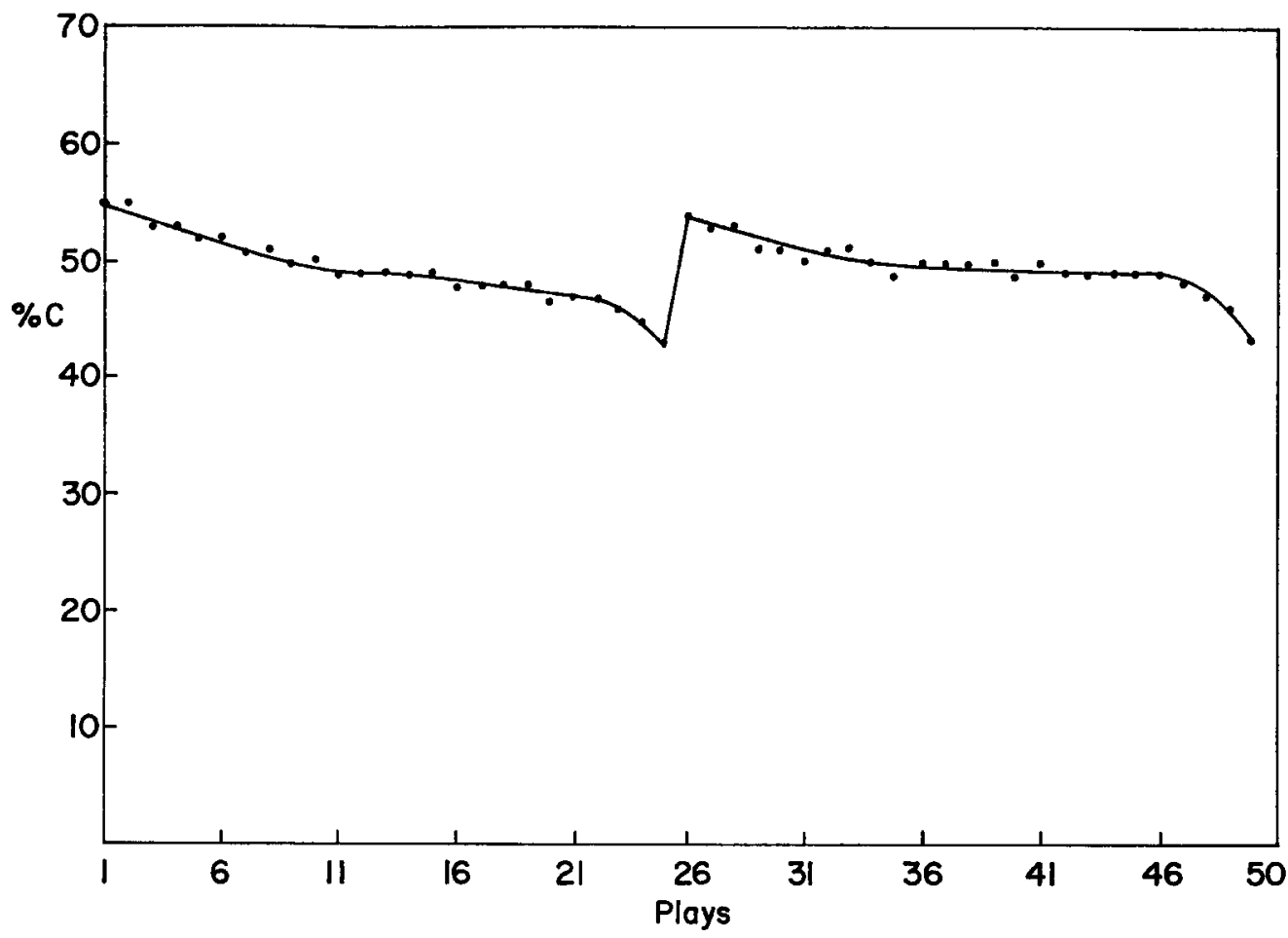

Fic. 1. Mean C frequencies for every play of a 50-run block averaged over all such blocks ( 649 pairs of players, 7,248 blocks).

magnitude of this difference is greater than the corresponding difference in the grand average of the first 25 plays, where the difference is, in fact, zero. This difference may, therefore, be due to a genuine end effect.

No end effect is observed in the ten-play run in Morehous' data. We do not know whether this exception is accidental or significant.

\section{Populations and Games}

The populations and games used in the experiments were as follows:

201: 70 pairs of male University of Michigan students, each 10 pairs playing one of the following seven games 300 times:
$(9,10,-10,-1) ;^{2}(1,10,-10,-9) ;(1,10$, $-10,-1) ;(1,2,-2,-1) ;(1,50,-50,-1)$; $(5,10,-10,-1) ;(1,10,-10,-5)$.

201W: Same as 201, played by 70 pairs of female students.

201C: Same as 201, played by 70 mixed sex pairs.

202: Same as 201, playing the following five games: $(1,20,-20,-1) ;(10,50,-50$, $-1)$; $(10,20,-20,-1)$; $(1,6,-6,-1) ;(1$, $1,-1,-1)$.

${ }^{2}$ A symmetric Prisoner's Dilemma game is designated by a quadruple $(R, T, S, P)$, where $R$ stands for the payoff received by two cooperating players (reward); $T$ the payoff to the lone defector (temptation); $\mathrm{S}$ the payoff to the lone cooperator (sucker's or saint's payoff); $\mathrm{P}$ the payoff to the two defecting players (punishment). 
203: Same as 201 with game matrix not displayed (the matrix can be inferred from announced payoffs).

204: Game $(1,2,-2,-1)$ played by 10 pairs of male students, each under the impression that the other player was playing Game $(1,50,-50,-1)$.

205: Each pair (male) played all of the seven games of Experiment 201, the game for each play being determined by a table of random numbers; 10 pairs, each playing 700 times.

206: Same as 205 with game matrix not displayed.

207: Same as 205 but with each game played 50 times in succession, the order of the games randomized (350 plays).

208: Game $(1,10,-10,-5)$ played by 9 male pairs 300 times.

209W: Game $(5,10,-10,-5)$ played by 31 female pairs 300 times.

210W: 100 pairs of female students, each
50 pairs playing one of the following games 50 times: $(5,15,-10,-5) ;(5,10,-15,-5)$. 211: 50 pairs of male students, each 10 pairs playing one of the following games: ${ }^{3}$ $(1,2,-2,-3) ;(1,2,-2,-5) ;(1,2,-2$, $-10) ;(1,2,-2,-20) ;(1,2,-2,-40)$.

211W: Same as 211 played by 50 pairs of female students.

\section{REFERENCES}

Rapoport, A., and A. M. Chammah. Prisoner's Dilemma: A Study in Conflict and Cooperation. Ann Arbor: University of Michigan Press, 1965.

Morehous, L. G. "One-Play, Two-Play, FivePlay, and Ten-Play Runs of Prisoner's Dilemma," Journal of Conflict Resolution, this issue, pp. 354-62.

3 The games in Experiments 211 and $211 \mathrm{~W}$ are not Prisoner's Dilemma games but Chicken games. The motivational structure of Chicken is similar (though not identical) to that of Prisoner's Dilemma. The Chicken games exhibit the start and end effects as clearly as Prisoner's Dilemma. 